\title{
Strengthening of materials by vibroimpact and combined methods with previous electrochemical processing
}

\author{
Alexander I. Boldyrev ${ }^{1, *}$, Alexander A. Boldyrev ${ }^{1}$, and Oleg N. Fedonin ${ }^{2}$ \\ ${ }^{1}$ Voronezh State Technical University, 14, Moscow Avenue, 394026, Voronezh, Russia \\ ${ }^{2}$ Bryansk State Technical University, 7, 50-letiya Octyabrya Blvd, 394026, Bryansk, Russia
}

\begin{abstract}
The authors examine capabilities of vibroimpact strengthening after electrochemical processing of materials, also getting guaranteed cold work of the surface during simultaneous anodic dissolution and mechanic calibration. They propose the technique of electrochemical mechanical processing. This article contains the results of experimental investigations. This technique passed evaluation test during production of shell cases with high accuracy and guaranteed hole cold work. The received results give ground for affirmation that electrochemical processing that proceeds hardening enables great extension of technological capabilities of this method and successful continuation investigations directed at creation of lighter constructions with higher ultimate resistance at reversed loads.
\end{abstract}

\section{Introduction}

Vibration technologies became a frequent practice in industry especially at creation of physicomechanical properties in surface layer (strengthening) that are necessary for increase of material endurance limit during repeated loadings. The performed experiments showed that for maximum endurance of metals during multicycle impact before strengthening it is necessary to have constant (in particular minimum) imposed stresses from previous processing. This helps to avoid overcoldwork of the surface and significantly raise ultimate resistance of the material.

Electrochemical dimensional processing (EChDP) enables removing of imposed stresses in the surface layer or stabilization of their amount and sign within batch of blank parts. The process of vibroimpact strengthening (VS) is influenced by dancing of hit energy, state of dynamic system and other factors preventing from guaranteed equal cold work of surface within batch of blank parts. Stabilization of strengthening final results can be achieved by application of combined influence on the surface by adjustment of rough tolerance previous to gauge element with the help of anodic dissolution and subsequent coldworking of the surface $[1,2]$.

\footnotetext{
*Corresponding author: alexboldyrev@mail.ru.
} 


\section{Investigation of vibroimpact strengthening modes for alloys after electrochemical dimensional processing (EChDP)}

The investigations were performed on 3 groups of material: steels $-40 \mathrm{CrNiMoA}\left(\sigma_{\mathrm{B}}=1100\right.$ $\mathrm{MPa}), 0 \mathrm{CrNi} 3 \mathrm{MoVA}\left(\sigma_{\mathrm{B}}=1400 \mathrm{MPa}\right), \mathrm{CrNi} 70 \mathrm{MoWTiAlNb}$ (after annealing); aluminum alloys - AVT1, V95; titanium alloys VT3-1, VT8. One pattern batch was produced by mechanical methods (milling, grinding, etc). Microhardness within every batch varied not more than by $10 \%$. Alteration of surface finish for every material in all batches was preserved within $10 \%$.

In 3 patterns from every batch of every material axial residual stresses were measured before strengthening. The investigated materials were processed according to standard programs of PC and produced consistent results in the amount of these stresses as well as in their sign.

Modes of vibroimpact strengthening were calculated according to techniques described in the investigations [3]. Modes training on the test bed showed that achievement of the same cold work level after EChDP and after mechanical processing requires less vibration amplitude and processing time (Table 1). The last-mentioned perhaps can be explained by small amount of residual stresses after EChDP and by the absence of congenital effects after the previous mechanical processing (MP).

Table 1. Modes of vibroimpact strengthening.

\begin{tabular}{|c|c|c|c|c|c|}
\hline Pattern material & $\begin{array}{c}\text { Vibration } \\
\text { frequency, } \\
\mathrm{Hz}\end{array}$ & $\begin{array}{c}\text { Vibration } \\
\text { amplitude, } \\
\mathrm{mm}\end{array}$ & $\begin{array}{c}\text { Pin } \\
\text { diameter, } \\
\mathrm{mm}\end{array}$ & $\begin{array}{c}\text { Mix } \\
\text { propor- } \\
\text { tion }\end{array}$ & $\begin{array}{c}\text { Time of } \\
\text { strengthening, } \\
\text { min }\end{array}$ \\
\hline 40CrNiMoA & 15 & 6 & $4-6$ & $1: 1$ & 15 \\
\hline 0CrNi3MoVA & 18 & 6,5 & $4-6$ & $1: 1$ & 15 \\
\hline CrNi70MoWTiAlNb & $15-16$ & 6 & $3-4$ & $1: 1$ & 20 \\
\hline AVT1, V95 & $20-22$ & 4,5 & $3-4$ & $1,5: 1$ & 30 \\
\hline VT3-1, VT8 & $25-28$ & 5 & $3-4$ & $1,5: 1$ & 20 \\
\hline
\end{tabular}

Hardened at these modes patterns had better results stability in depth of coverage and amount of residual stresses (Table 2), this proves the possibility of achieving the needed surface cold work after EChDP.

Analysis of Table 2 shows that vibroimpact strengthening with previous EChDP enables stable characteristics of microlevel and cold work. That's grounds for recommendation of EChDP as operation proceeding vibroimpact strengthening because of decrease in possibility of overcoldwork which can dramatically lower endurance strength of the alloy.

Fig. 1 shows peak characteristics of alloys endurance at multicycle loadings (base

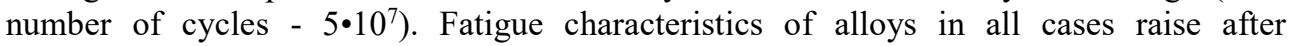
strengthening. Besides after EChDP these characteristics are not lower (within the accuracy of measurements) than after previous MP. Similar results were received for other alloys as well. 
Table 2. Cold Work Stability after Mechanical (MP) and Electrochemical Dimensional Processing (EChDP).

\begin{tabular}{|c|c|c|c|c|c|c|}
\hline \multirow[t]{2}{*}{ Material } & \multirow{2}{*}{$\begin{array}{l}\text { Type of } \\
\text { previous } \\
\text { processing }\end{array}$} & \multicolumn{2}{|c|}{$\begin{array}{l}\text { Alteration of cold } \\
\text { work inmost depth } \\
\text { in pattern batch }\end{array}$} & \multicolumn{2}{|c|}{$\begin{array}{l}\text { Alteration in } \\
\text { maximum value of } \\
\text { imposed stress } \\
\text { bedding }\end{array}$} & \multirow{2}{*}{$\begin{array}{c}\begin{array}{c}\text { Degree } \\
\text { of cold } \\
\text { work }\end{array} \\
\%\end{array}$} \\
\hline & & $\mathrm{mm}$ & $\%$ & $\mathrm{MN} / \mathrm{m} 2$ & $\%$ & \\
\hline \multirow{2}{*}{ 40CrNiMoA } & MP & $0.03-0,10$ & 70 & $320-380$ & 16 & 30 \\
\hline & EChDP & $0,05-0,07$ & 28,5 & $400-430$ & 7 & 30 \\
\hline \multirow{2}{*}{ CrNi70MoWTiAlNb } & MP & $0,02-0,08$ & 100 & $350-430$ & 18,6 & \\
\hline & EChDP & $0,03-0,07$ & 57 & $400-430$ & 7 & \\
\hline \multirow{2}{*}{ AVT1 } & MP & $0,05-0,12$ & 58 & $130-160$ & 18,8 & \\
\hline & EChDP & $0,05-0,09$ & 44 & $150-170$ & 12 & \\
\hline \multirow{2}{*}{ VT3-1 } & MP & $0,01-0,09$ & 89 & $220-600$ & 63 & 14 \\
\hline & EChDP & $0,02-0,05$ & 60 & $240-420$ & 43 & 14 \\
\hline
\end{tabular}

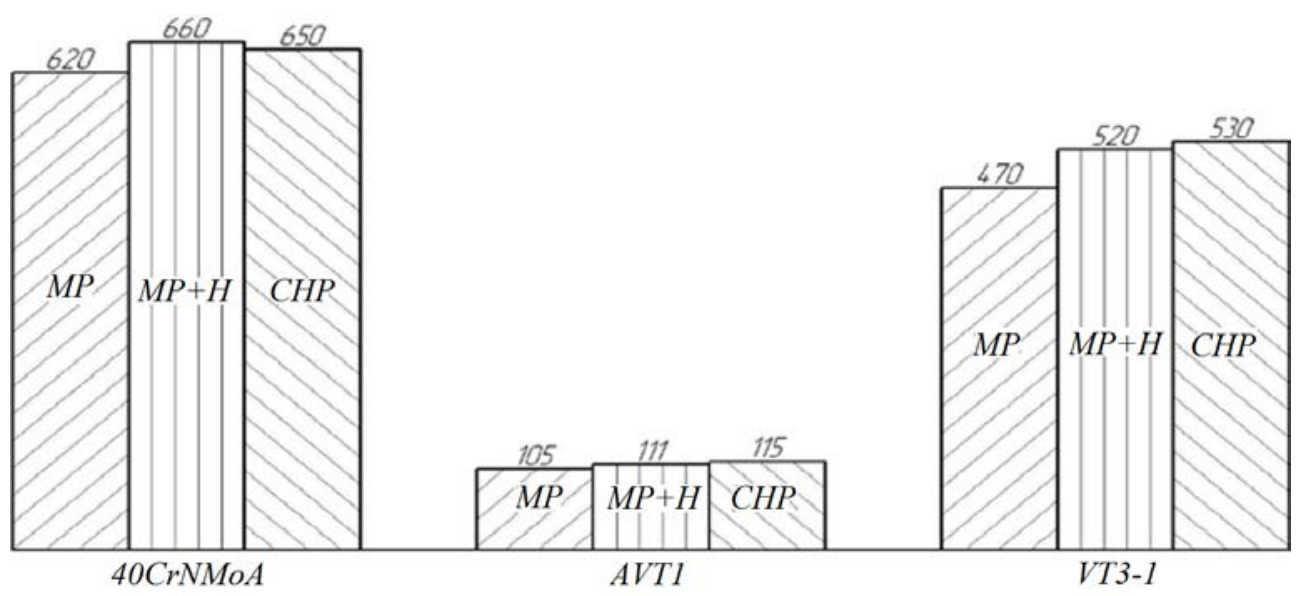

Fig. 1. Alteration of Endurance Strength $\left(\mathrm{MN} / \mathrm{m}^{2}\right)$ in Alloys after Various Techniques of Processing.

With the help of correspondences presented in [4] it is possible to calculate capability of mass reduction for some simple-shaped workpieces operating at multicycle loadings by stabilization of final hardening rate after EChDP. 


\section{Combined technique for production of guaranteed surface cold work}

The performed investigations showed that peak index of increase in endurance strength has its value for every material. Besides alteration in cold work level even by several per cent causes dramatical decrease in workpiece endurance limit. For example for 40CrNiMoA steel the maximum value of endurance limit corresponds to col work of $16 \%$, decrease or increase of cold work by $7 \%$ (Table 2) lowers endurance by $32,7 \%$ and $14,2 \%$, consequently.

At Voronezh State Technical University we worked out and implemented in existing industry the technique of combined strengthening processing (CSP) providing optimum cold work value to a tolerance of not more than $1 \%$. The essence of this method is that processing is performed with application of combined tool electrode made from tool for electrochemical processing (electrode 2) and gauge tool that are isolated from one another (Fig. 2).

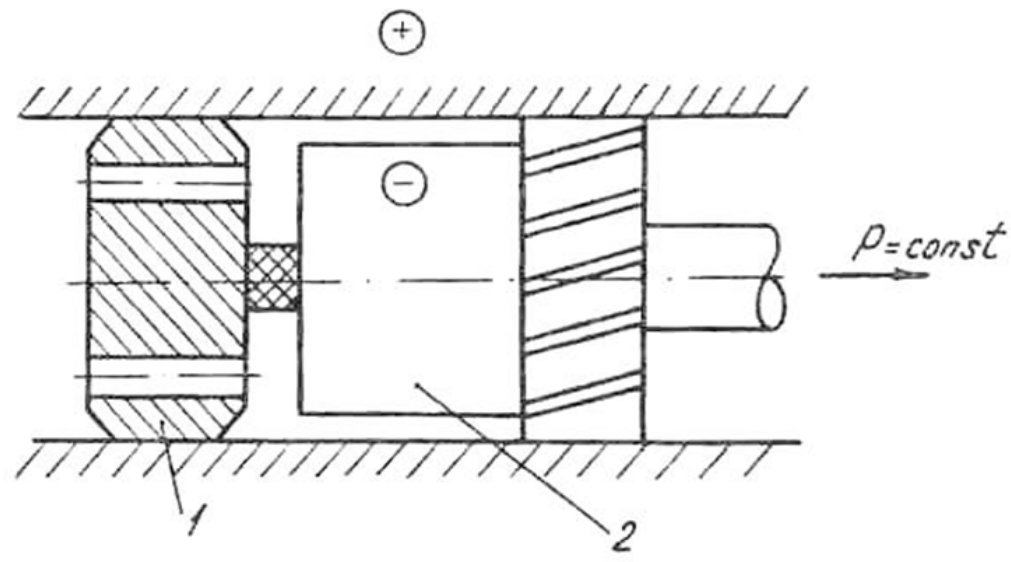

Fig. 2. Diagram of Combined Processing: 1 - gauge element, 2 - electrode.

The motion of combined tool is fulfilled at constant central force with optimum amount of cold work found by experiments for different materials:

$$
P=\frac{\pi}{200} \cdot p_{c} \cdot d_{h} \cdot d_{g} \cdot\left(1+\frac{f}{\operatorname{tg} \alpha}\right) \cdot \sqrt[n]{\frac{U_{c w} \cdot H B_{0}}{100 \cdot A}},
$$

where: $p_{c}$ - contact pressure; $d_{h}$ - hole diameter after EChDP; $d_{g}$ - diameter of gauge element; $f$ - index of friction; $\alpha$ - bevel lead angle of gauge element; $U_{c w}$ amount of optimum cold work; $H B_{0}$ - hardness corresponding to cold-worked state of metal; $A, n$ - empirical coefficients.

In this case regardless of initial cold work and tolerance non-uniformity the electrode will dissolve metal before gauge element up to the moment when tolerance equals calculated value and it is possible due to axial force to move the combined tool along the axis of workpiece. Calculations of processing modes are performed by the procedure presented in [5]. 
The performed investigations showed that for $40 \mathrm{CrNiMoA}$ steel optimum cold work can be preserved with tolerance of not more than $1 \%$. This ensures the increase in endurance limit by $7 \%$ in comparison with MP. Besides new technique of feed control by constant effort solves the problem of accuracy increase for channels of any length providing processing error within 7 th quality grade of National State Standard.

Also as a result of plastic deformation performed by gauge element during combined processing we have qualitative improvement of surface layer. Tears and detachments typical for previous EChDP are practically absent, that is effect of heal defects. The structure of levels bearing against the surface undergoes definitive changes. These changes consist in texture formation and in some cases in significant grain refining. The structure of such surface layers approaches the structure of amorphous metallic materials, this fact perhaps explains the increase in product operational characteristics [6].

This method got approval at production of muffs possessing high accuracy and assured hole cold work. The received results give reason for affirmation that electrochemical processing before strengthening enables significant expansion for technology option of the method and successfully continue the work for production of lighter constructions with increased tensile strength at alternating load.

\section{Conclusions}

The efficiency of vibroimpact strengthening significantly raises if it is used after EChDP. Application of vibroimpact strengthening eliminates the main defect of EChDP (reduction of endurance in process materials) and enables mass reduction for loaded workpieces.

Capabilities of strengthening technology significantly increase when combined processing is used. For example the proposed technique for surface forming in uniform cross section channels by combined tool enables achievement of calculated cold work value corresponding to maximal rise in alloy endurance limit. Due to it we can expect decrease in construction mass up to $20 \%$ with preservation of their hardness in comparison with MP. In the case of standard hardening mass reduction won't exceed the half of this value.

Taking into account general trend of machine-building to development of combined technological processes it is possible to say that popular strengthening techniques will become front kinds of impact that widen technology options of machine-building.

\section{References}

1. A.I. Boldyrev, V.P. Smolentsev, Method of electrochemical treatment (USSR Patent №1085734, 1984)

2. V.V. Dolgushin, O.V. Kozlova, A.I., V.P. Smolentsev, Boldyrev, Method of electrochemicalmechanical treatment of channels and device for its implementation (Russian Patent №2251472, 2005)

3. A.V. Kirichek, D.L. Soloviev, A.G. Lazutkin, Technology and equipment of staticpulse processing by surface plastic deformation. Library of the technologist. (Mechanical Engineering, Moscow, 2004)

4. A.V. Bondar, Quality and reliability. (Mechanical Engineering, Moscow, 2007)

5. A.I. Boldyrev etc., Theory of electrical and physicochemical methods of processing. Part 2: Processing of materials using highly concentrated energy sources and combined methods. (Voronezh State Tecnical Univercity, Voronezh, 2008)

6. I.V. Zolotuhin, Physical properties of amorphous metallic materials. (Metallurgy, Moscow, 1986) 